\title{
Instructions
}

You are taking part in an experiment involving financial forecasts. The instructions are simple and if you follow them carefully and make good decisions, you can earn some money, which will be paid to you after the experiment. The currency used in this experiment is called "eurux". If anything is unclear at any time, feel free to raise your hand and ask the experimenter any questions you may have. Please do not talk to other participants during the entire experiment. During the experiment you will receive information regarding the price evolution of an asset across several periods.

You will participate in several independent sequences of periods. Each time that a sequence ends a new one starts. The length of the sequence may vary. The experiment will last a maximum of 90 minutes.

\section{Information and forecast}

For each period you have to insert your best guess about the price that the asset will have at the end of the current period.

Price sequences are the result of experimental asset markets played some months ago in the laboratory by real participants. Furthermore, you will receive information regarding the prevailing interest rate that participants were receiving on the money not used in the asset market.

Your objective is to forecast the evolution of the asset price across periods.

In order to make your guess, you have to pay attention to three pieces of information provided by the program:

1. The asset price of the past period. This is the last market price of the financial asset

2. The interest rate announced in the past period

3. The current interest rate for this period

With this information you have to insert your guess about the price that the asset will take at the end of the current period.

For example. Suppose you are in period 3 of the second sequence of periods. The program tells you that in period 2 the last realized price was of $\mathbf{2 0 0}$ Eurux. Additionally it tells you that the interest rate for period 2 was $9 \%$. Finally, the program tells you that the current interest rate for period 3 is $6 \%$. You have to indicate the price you think the asset will take at the end of period 3. 


\section{Participant payment}

After inserting your price prediction, the program will compute the distance between your prediction and the real market price at the end of the period.

Based on the following table, your earnings will be totaled up and communicated to you at the end of the experiment.

\begin{tabular}{|l|l|}
\hline Level of accuracy & Earnings to individual submitting prediction \\
\hline Within $5 \%$ of the real price & $2.5 €$ \\
\hline Within $12.5 \%$ of the real price & $1 €$ \\
\hline Within $25 \%$ of the real price & $0.5 €$ \\
\hline
\end{tabular}

Table 1B: Payment Schedule for the accuracy of predictions

Here is an example:

Suppose we are in period 4. You inserted a price of 300 Eurux as your prediction for the end of the current period. The price turns out to be equal to 350 Eurux.

Since your forecast was $16 \%$ above the real market price, for this period your earnings are equal to $0.5 €$.

The sum of your earnings per period will determine your total earnings in the experiment

\section{Trial Periods}

Before starting with the real experiment, we will practice for one sequence of 5 periods. This sequence will not count toward your earnings for the experiment.

During these trial periods, please raise your hand if you have any questions.

YOU ARE NOT ALLOW TO COMMUNICATE WITH ANY OTHER PARTICIPANT. The use of mobile phones is totally forbidden. 